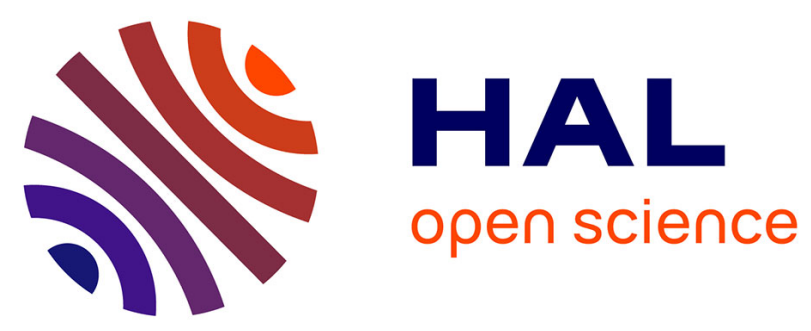

\title{
Developing a MEMS device for high-throughput multi-parameter single cell biophysical analysis
}

Quentin Rezard, Gregoire Perret, Jean Claude Gerbedoen, Deniz Pekin, Fabrizio Cleri, Dominique Collard, Chann Lagadec, Mehmet Tarhan

\section{To cite this version:}

Quentin Rezard, Gregoire Perret, Jean Claude Gerbedoen, Deniz Pekin, Fabrizio Cleri, et al.. Developing a MEMS device for high-throughput multi-parameter single cell biophysical analysis. 2021 IEEE 34th International Conference on Micro Electro Mechanical Systems, MEMS 2021, Jan 2021, Gainesville (on line), United States. pp.494-497, 10.1109/MEMS51782.2021.9375176 . hal-03195317

\section{HAL Id: hal-03195317 https://hal.science/hal-03195317}

Submitted on 17 Sep 2021

HAL is a multi-disciplinary open access archive for the deposit and dissemination of scientific research documents, whether they are published or not. The documents may come from teaching and research institutions in France or abroad, or from public or private research centers.
L'archive ouverte pluridisciplinaire HAL, est destinée au dépôt et à la diffusion de documents scientifiques de niveau recherche, publiés ou non, émanant des établissements d'enseignement et de recherche français ou étrangers, des laboratoires publics ou privés. 


\title{
DEVELOPING A MEMS DEVICE FOR HIGH-THROUGHPUT MULTI- PARAMETER SINGLE CELL BIOPHYSICAL ANALYSIS
}

\author{
Quentin Rezard ${ }^{1,2}$, Grégoire Perret ${ }^{2,3}$, Jean Claude Gerbedoen ${ }^{2,3}$, Deniz Pekin ${ }^{2,4}$, \\ Fabrizio Cleri ${ }^{1}$, Dominique Collard ${ }^{2,3}$, Chann Lagadec ${ }^{2,5}$ and Mehmet C. Tarhan ${ }^{1,2}$ \\ ${ }^{1}$ Univ. Lille, CNRS, Centrale Lille, Yncrea, Univ. Valenciennes, UMR 8520-IEMN, Lille, FRANCE \\ ${ }^{2}$ CNRS, IIS, COL, Univ. Lille, SMMiL-E Project, Lille, FRANCE \\ ${ }^{3}$ LIMMS/CNRS-IIS, UMI 2820, The University of Tokyo, Lille, FRANCE \\ ${ }^{4}$ INSERM, UMR-S 1172 - JPARC, Lille, FRANCE and \\ ${ }^{5}$ CANTHER, INSERM UMR1277, Lille, FRANCE
}

\begin{abstract}
We introduced a MEMS device to perform direct measurements on electrical and mechanical properties of single cancer cells. Working in a continuous flow format permits high-throughput measurements. The device design allows us to define fixed or movable electrodes as part of the side-walls of an embedded microchannel. The stable air-liquid interface at micro-sized gaps between the electrodes and the channel wall provide flow continuity without causing any leakage problems. This unified processing approach allows us to define optimized electrode pattern configuration for both electrical and mechanical characterization areas. Moreover, the movable electrode is in direct contact with passing cells which enables direct sensing during compression. The device can perform both electrical and mechanical measurements on single cells in a continuous flow as demonstrated and also validated by optical control measurements. The proposed method aims at providing high-throughput biophysical cytometry, in an optics- and marker-free way, for cancer cell evaluation.
\end{abstract}

\section{KEYWORDS}

Biophysical cell characterization, high-throughput measurements, single-cell analysis, cancer.

\section{INTRODUCTION}

Characterizing circulating tumor cells (CTCs) has been an essential target for cancer diagnostics. Membrane proteins, e.g. epithelial cell adhesion molecule (EpCAM), have been demonstrated as biomarkers to detect CTCs. However, when a cell undergoes a transition from epithelial to mesenchymal, such approaches can miss detecting these potentially invasive cells. Unfortunately, there is no membrane protein as a universal biomarker for cell invasiveness. As an alternative indicator, some studies propose biophysical properties as potential biomarkers because mechanical properties of cells can potentially reflect the state of their health [1,2].

Due to the high heterogeneity of cancer cells, sensitive single-cell analysis is crucial for an appropriate detection and analysis method. Moreover, the scarce concentration of CTCs demands the method to provide high-throughput. For diagnostic purposes, the method should also be suitable for routine tests, and thus, be practical, cost- and laborefficient. Many techniques have been developed targeting mechanical characterization by providing sensitivity (e.g. AFM) or speed (e.g. deformability cytometry). However, there still is a great demand for practical and highthroughput methods to analyze the biophysical properties of single cells routinely.

Here, we are introducing a MEMS device performing electrical characterization with impedance measurements and mechanical characterization with measurements on cells under compression during a continuous flow. These direct measurements of cell biophysical properties allow the proposed method to be label- and optics-free for providing practicality while working in a continuous-flow format permits high-throughput measurements. As a result, the proposed device can provide information on both electrical and mechanical properties of single cancer cells (Fig. 1).

\section{METHODS}

\section{Device description}

The proposed device is composed of two layers: a PDMS layer assembled on a MEMS layer. The PDMS layer has an inlet to inject a cell solution and an outlet to connect to a vacuum pump for controlling the flow along the microfluidic channel embedded in the MEMS layer.

The MEMS layer is the functional layer of the proposed device fabricated using a 2-mask process similar to the device detailed elsewhere [3]. The fabrication process consists of photolithography and dry etching steps on both sides of an SOI wafer $(30 / 2 / 350 \mu \mathrm{m})$ followed by a wet silicon dioxide removal. The MEMS layer consists of three parts (Fig. 1a):

(i) A microfluidic channel is formed between silicon walls (etched until the BOX layer) on the sides, the backside silicon layer as the bottom and the PDMS slab as the top. Connecting the inlet and the outlet of the PDMS layer, the microfluidic channel is used to handle and characterize cells.

(ii) Electrical characterization area includes electrodes facing at the microfluidic channel. These electrodes are fabricated at two sides of the channel. Electrodes are connected to a PCB via connection pads.

(iii) Mechanical characterization area consists of a converging wall at one side and a movable sensing tip at the other side of the channel. The tip is connected to a displacement sensor. This capacitive differential sensor measures cell properties during compression. Similar to electrodes of the electrical measurement area, three electrodes of the displacement sensor are wirebonded to the PCB via pads. 


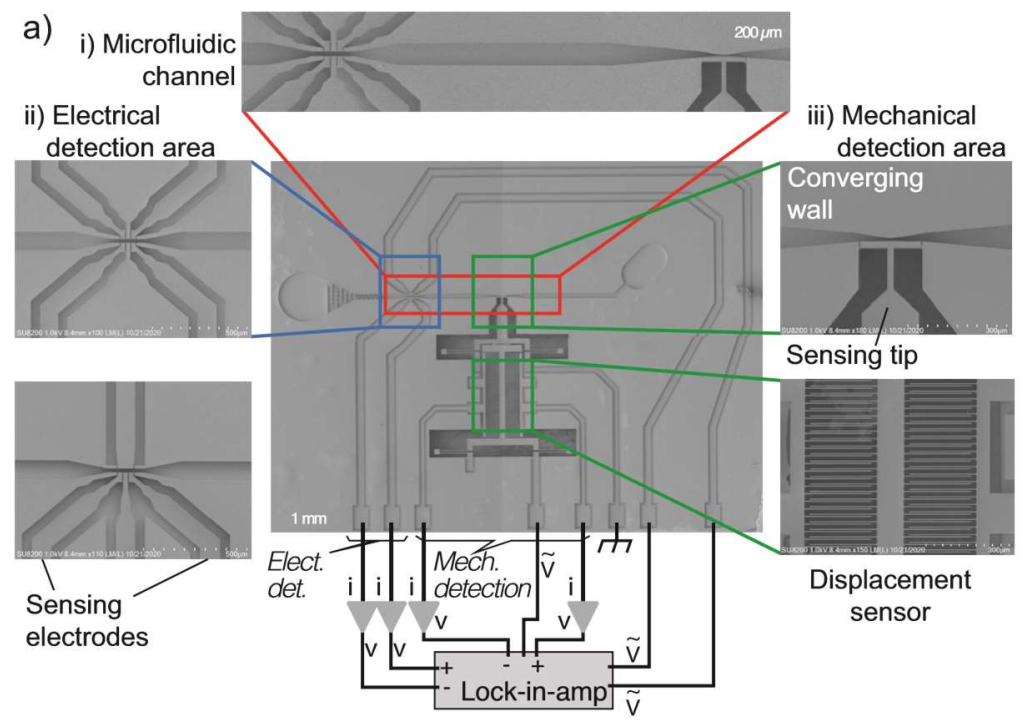

\section{b) Working principle}

(i) Cell approaching to the elect. det. area

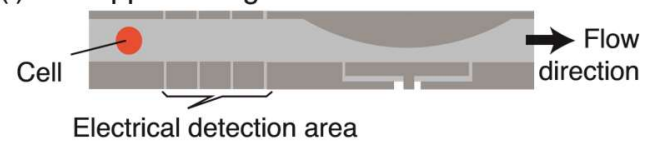

(ii) Cell electrical detection \& measurement

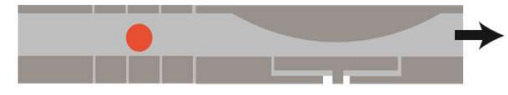

(iii) Cell mechanical detection \& measurement

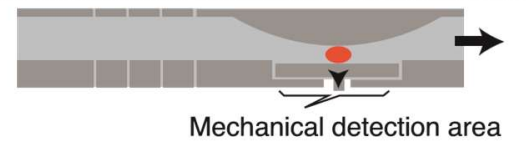

(iv) Next cell approaching

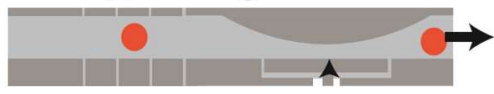

Figure 1: a) A general SEM view of the proposed device. The functional part of the device consists of 3 parts:

(i) a microfluidic channel embedded in the top layer of an SOI wafer to handle cells, (ii) an electrical detection area to perform electrical measurements in continuous flow and (iii) a mechanical detection area to stimulate cells mechanically during simultaneous measurements. b) The working principle shows how cells are first characterized electrically and then mechanically in a continuous flow.

\section{Working principle}

The proposed device targets single-cell measurements during a continuous flow to provide high-throughput. Thus, both electrical and mechanical measurements can be performed continuously in real-time (Fig. 1b). The designed device keeps the detecting electrodes at minimal immersion in liquid for better performance. We use airliquid interfaces at the characterization areas to keep the crucial mechanical and electrical elements out of the channel while the tips of the electrodes maintaining access to the channel for measurements.

Cells inserted via the inlet flow through the 100$\mu$ mwidth channel and reach the electrical characterization area where the channel width drops to $25 \mu \mathrm{m}$. Electrical characterization is performed using two pairs of electrodes (or two sensing electrodes with one common electrode for the driving signal) working in differential mode with a grounded wall structure separating electrode pairs. Cells passing between the electrodes cause a change in the current that is detected in real-time. Electrodes (and the wall in between) are $25 \mu \mathrm{m}$ in width and have $4 \mu \mathrm{m}$ of a gap between each other. The $30-\mu \mathrm{m}$ top layer of the SOI wafer defines the height of electrodes. The 4- $\mu \mathrm{m}$ gap between the electrodes forms a stable air-liquid interface due to the surface tension of the liquid preventing any leakage issues. A sinusoidal signal $\left(1 \mathrm{~V}_{\mathrm{p}-\mathrm{p}}\right)$ is applied on non-sensing electrodes with a lock-in-amplifier (Zurich Instruments HF2LI). Sensing electrodes are first connected to a transimpedance amplifier (Zurich Instruments HF2TA), with a gain of $10^{5}$, before fed into the lock-inamplifier in the differential mode. This impedance cytometry setup allows us to perform measurements simultaneously at three different frequencies for providing information on cell size, membrane capacitance and cytoplasm resistivity. Here we demonstrate only the cell size measurements.

After the electrical characterization area, cells reach the mechanical characterization area. This part of the device consists of a converging wall structure to provide mechanical cell stimulation with compression cycles in a continuous flow and a movable sensing tip performing simultaneous measurements on cells during compression. To minimize the liquid effect, the tip is kept at minimal immersion into the channel. The surface tension of the liquid in the channel allows a stable air-liquid interface to avoid leakage. The space around the tip is defined by the etched oxide layer $(2 \mu \mathrm{m})$ under, etched silicon $(4 \mu \mathrm{m}$ width) on the sides and molded PDMS ( $4 \mu \mathrm{m}$ height) above. The tip length $(190 \mu \mathrm{m})$ is long enough to measure cell compression all along the converging wall which changes the channel width from $25 \mu \mathrm{m}$ to $10 \mu \mathrm{m}$ and then back to $25 \mu \mathrm{m}$. The capacitive displacement sensor consists of a movable center electrode (connected to the tip) with two fixed side electrodes. A sinusoidal signal (5Vp-p, $100 \mathrm{kHz})$ is applied on the mobile electrode creating a current between the arm of the central electrode and the side ones according to the relative position of them. Four springs define the detection sensitivity and hold the mobile part suspended.

\section{Setup}

Experiments are performed on an upright microscope stage by placing the PCB with the wirebonded device. The outlet of the PDMS slab is connected to a vacuum pump (Elveflow AF1) and the electrodes are connected to the lock-in-amplifier at different channels. Signals obtained from sensing electrodes are first amplified using transimpedance amplifiers before feeding in the lockinamplifier. Experiments are monitored using a camera (Andor, Zyla) only for confirmation of the measurements.

\section{Biological materials}

SUM159PT, a triple-negative breast cancer cell line, is tested with the prosed method. Cells are grown in monolayer conditions up to subconfluence. After being trypsinized to obtain a homogenous cell suspension solution, they are put in a PBS $1 \mathrm{x}$ solution and passed through a $40-\mu \mathrm{m}$ filter before used in the experiment. 
a)

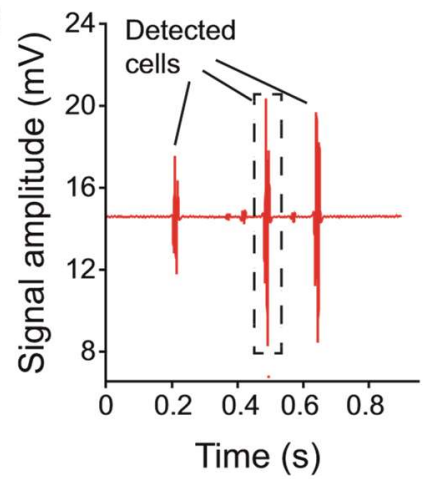

d)

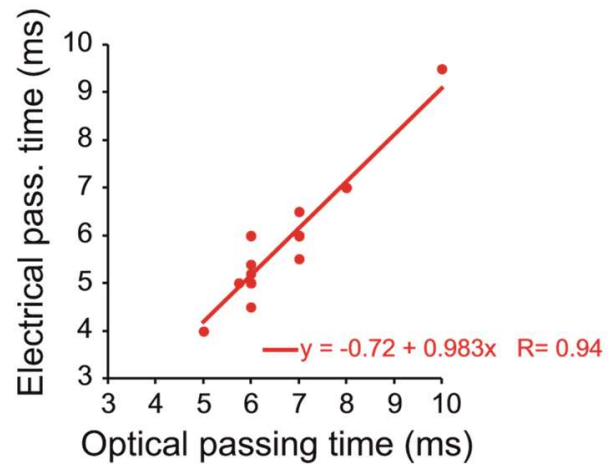

b)

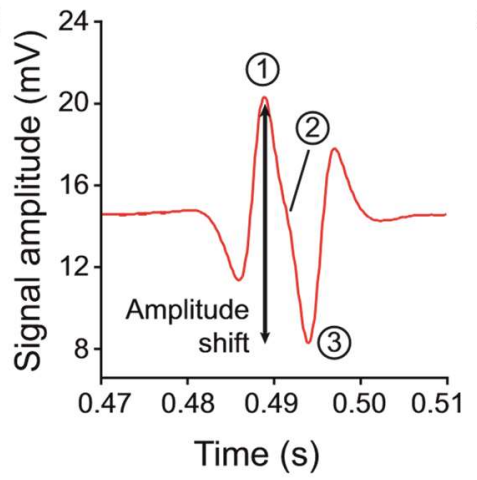

c) Passing Applying

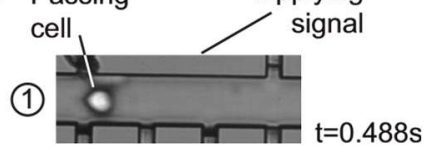

(2)

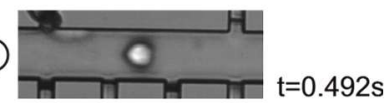

(3)

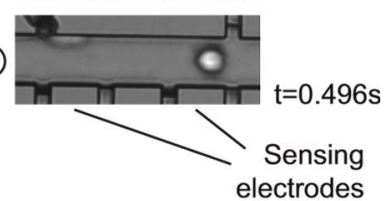

e)

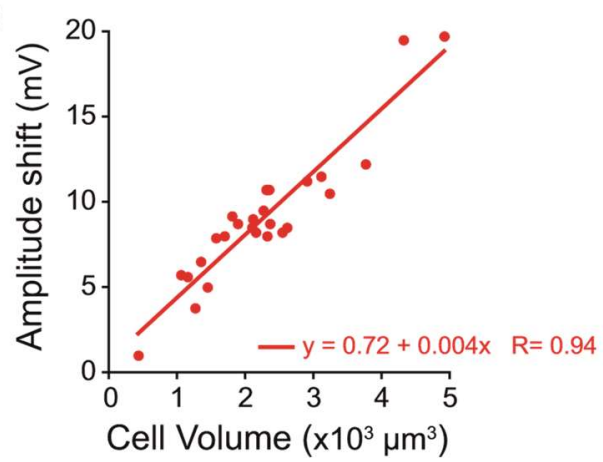

Figure 2: a) Cells flowing through the channel were detected at the electrical characterization area as spikes in the impedance measurements (the real component at $700 \mathrm{kHz}$ ). b) A closer look at one of the detected cells (corresponding to the dashed rectangle at (a)) shows the minimum and maximum amplitude values corresponding to positions of sensing electrodes. c) Visualization of the characterization area shows the corresponding electrical measurements. Scale bar: 20 $\mu \mathrm{m}$ d) Accurate real-time measurements were examined comparing the passing time obtained optically and electrically.

e) Signal amplitude shift at $700 \mathrm{kHz}$ due to a passing cell correlated well with cell dimension.

\section{Experimental procedure}

The assembled device on a PCB is placed on the microscope stage and all connections (electrical and fluidic) are secured. First, water, and then, PBS solution (or culture media depending on the experiment) are injected to fill the channel and the tubing until the vacuum pump. Then, $5 \mu 1$ of the cell solution is dropped on the inlet. The flow inside the channel is controlled by the vacuum pump to create the desired steady flow. Although the proposed system does not require optics for detection, all experiments are monitored with the microscope and recorded with a camera. Thus, both characterization areas are observed and tested separately.

\section{RESULTS AND DISCUSSIONS}

The proposed method was tested using SUM159PT breast cancer cell lines. Successful cell detection was achieved at both electrical (Fig. 2a) and mechanical characterization areas (Fig. 3a). Each peak corresponds to a passing cell detected either by the electrodes facing the channel (Fig. 2b,c) or by the displacement sensor moving due to a compressed cell (Fig. 3b,c).

Detected cell motion obtained by the real-time electrical measurements were compared with optical results to see the accuracy of the performed measurements. The passing time in the electrical characterization area, measured as the time between the maximum and the minimum amplitude values, showed good agreement with the measurements obtained using the microscope view (Fig. 2d).
The mechanical characterization area measurements were tested similarly by comparing the optical and mechanical passing times. The mechanical passing time was defined as the time from the displacement sensor started sensing compressed cells to the end of the compression. Similar to the electrical case, real-time measurements were accurate enough to be wellcorrelated with the values detected optically (Fig. 3d).

Electrical impedance measurements at different frequencies provide information on various cell properties [4]. Although we could run three different frequencies to obtain information on cell dimension, membrane capacitance and cytoplasm resistivity, here, we demonstrated only the measurements on cell dimension as it is the crucial property for investigating the mechanical cell properties later for the combined measurements. The real component of the measurements performed at $700 \mathrm{kHz}$ showed good correlation with cell volume obtained optically (Fig. 3e). We note that the outof-plane dimensions of the cells were approximated according to the $2 \mathrm{D}$ images.

Measurements targeting mechanical properties of cells were performed at the mechanical characterization area. Cells were compressed by the converging wall while moving with the flow. The movable sensing tip connected to the sensor was displaced according to the mechanical properties of the passing cell during applied mechanical stimulation by the wall and the flow (Fig. 3e). As all cells were compressed down to $10 \mu \mathrm{m}$, the compression rate was based on the initial dimension of each one. However, the 
a)

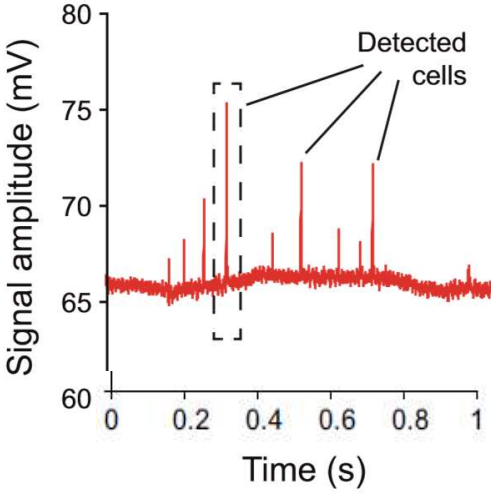

d)

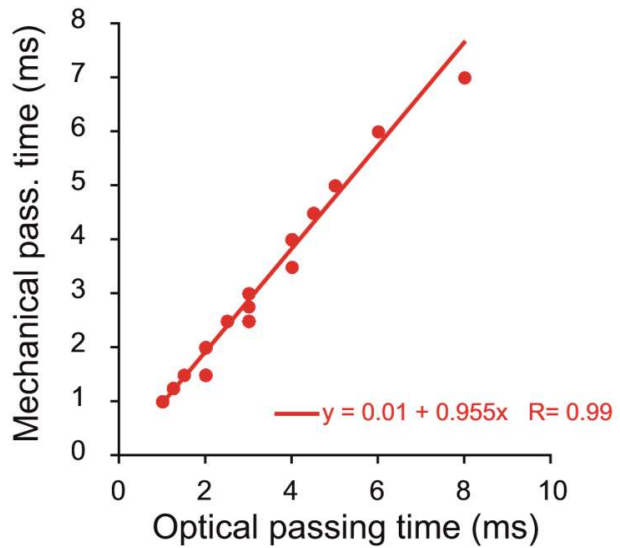

b)

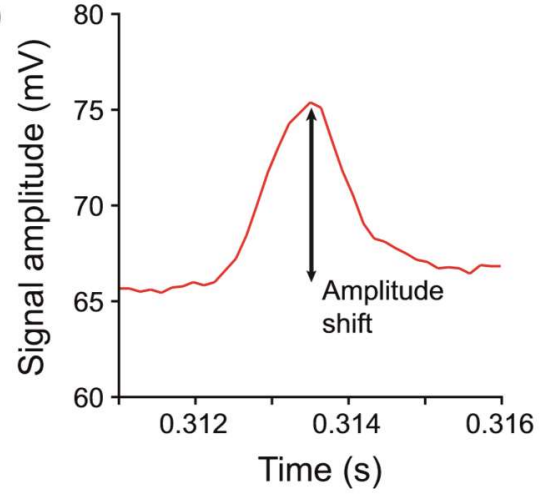

e)

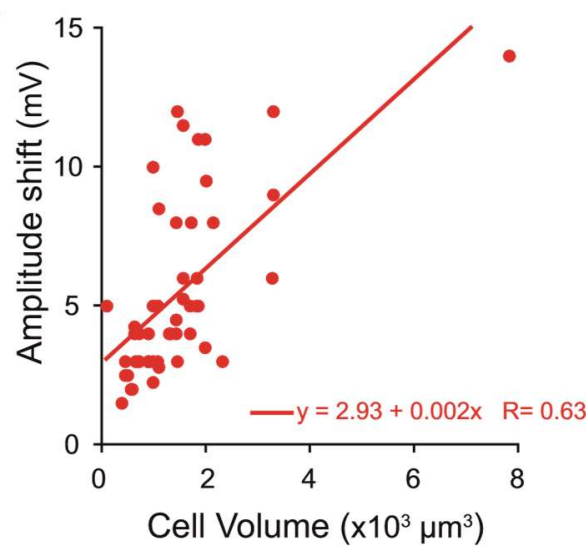

) Converging
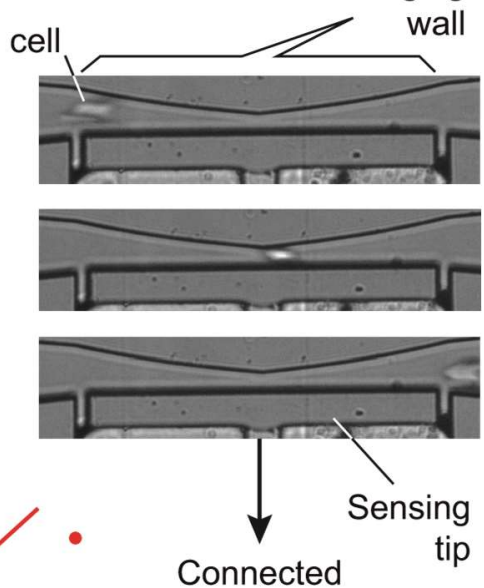

to the sensor

Figure 3: a) Cells flowing through the channel were detected at the mechanical characterization area as spikes in the mechanical measurements using a displacement sensor. b) A closer look at one of the detected cells (the dashed rectangle at (a)) shows the amplitude peak corresponding to the narrowest part of the channel during a compression cycle. c) Visualization of the characterization area shows compression cycle of a cell. Scale bar: $20 \mu \mathrm{m}$ d) Accurate realtime measurements were examined comparing the passing time obtained optically and mechanically. e) Signal amplitude shift during cell compression cycle provided information on the mechanical characteristics of the compressed cell.

result showed a variation among measurements on cells even at similar dimensions. This can be caused by the heterogeneity of the cells. We note that demonstrating highspeed cell passage $(<10 \mathrm{~ms}$ along the compression area) impairs the quality of the optical view which results in poor measurements of the cell dimension unless a highspeed camera is used. This additional uncertainty should also be considered when reading Figure $3 \mathrm{e}$.

\section{CONCLUSIONS}

We introduced a MEMS device to perform direct measurements on electrical and mechanical characteristics of single cancer cells. By working in a continuous flow format, this device allows us performing measurements on single cells in less than $10 \mathrm{~ms}$ to provide high-throughput. Although both measurement types were shown separately to confirm with optical monitoring, the proposed method does not require any optical visualization for mechanical or electrical characterization. As a result, the proposed method suggests a practical, cost- and labor-efficient way of analyzing multiple biophysical parameters of single cells in a high-throughput format.

\section{ACKNOWLEDGEMENTS}

This work is in the framework of SMMiL-E activities (a joint project of CNRS, Institute of Industrial Science,
Centre Oscar Lambret and University of Lille). The authors acknowledge the French State-Region plan (CPER IRICL, Lille Interdisciplinary research Institute against cancer) for financial support and IRCL for hosting SMMiL-E. M. C.

Tarhan and Q. Rezard acknowledge I-SITE ULNE.

\section{REFERENCES}

[1] C. T. Lim, E. H. Zhou, \& S. T. Quek, Mechanical models for living cells-a review. J Biomechanics 39 , 195-216, 2006.

[2] S. E. Cross, Y.-S. Jin, J. Rao, \& J.K. Gimzewski, Nanomechanical analysis of cells from cancer patients. Nat Nanotechnol 2, 780-783, 2007.

[3] Y. Takayama, G. Perret, M. Kumemura, M. Ataka, S. Meignan, S. Karsten, et al., Developing a MEMS Device with Built-in Microfluidics for Biophysical Single Cell Characterization. Micromachines, 9(6), 275,2018

[4] S. Gawad, L. Schild, \& P. Renaud, Micromachined impedance spectroscopy flow cytometer for cell analysis and particle sizing. Lab on a Chip, 1(1), 7682,2001

\section{CONTACT}

*M.C. Tarhan, cagatay.tarhan@yncrea.fr 